\title{
Increased intrahepatic resistance in severe steatosis: endothelial dysfunction, vasoconstrictor overproduction and altered microvascular architecture
}

\author{
Sven Francque ${ }^{1,2, *}$, Wim Laleman ${ }^{3, *}$, Len Verbeke ${ }^{3}$, Christophe Van Steenkiste ${ }^{4}$, Christophe Casteleyn ${ }^{5}$, \\ Wilhelmus Kwanten ${ }^{2}$, Christophe Van Dyck ${ }^{2}$, Michiel D'Hondt ${ }^{2}$, Albert Ramon ${ }^{1,6,7}$, Wim Vermeulen ${ }^{2}$, \\ Benedicte De Winter ${ }^{2}$, Eric Van Marck ${ }^{8}$, Veerle Van Marck ${ }^{8}$, Paul Pelckmans ${ }^{1,2}$ and Peter Michielsen ${ }^{1,2}$
}

\begin{abstract}
Non-alcoholic fatty liver disease can progress to steatohepatitis and fibrosis, and is also associated with impaired liver regeneration. The pathophysiology remains elusive. We recently showed that severe steatosis is associated with an increase in portal pressure, suggesting liver flow impairment. The objective of this study is to directly assess total intrahepatic resistance and its potential functional and structural determinants in an in situ perfusion model. Male Wistar rats fed a control $(n=30)$ or a methionine-choline-deficient (MCD) diet $(n=30)$ for 4 weeks were compared. Liver tissue and serum analysis, in vivo haemodynamic measurements, in situ perfusion experiments and vascular corrosion casts were performed. The MCD group showed severe steatosis without inflammation or fibrosis on histology. Serum levels and liver tissue gene expression of interleukin (IL)- 6 , tumour necrosis factor- $\alpha, \mathrm{IL}-1 \beta$ and interferon- $\gamma$, liver tissue myeloperoxidase activity and liver immunohistochemistry with anti-CD68 and anti- $\alpha$ smooth muscle actin were comparable between groups, excluding significant inflammation. Flow-pressure curves were significantly different between groups for all flows (slope values: $0.1636 \pm 0.0605 \mathrm{~mm} \mathrm{Hg} / \mathrm{ml} / \mathrm{min}$ in controls vs $0.7270 \pm 0.0408 \mathrm{~mm} \mathrm{Hg} / \mathrm{ml} / \mathrm{min}$ in MCD-fed rats, $P<0.001$ ), indicating an increased intrahepatic resistance, which was haemodynamically significant (portocaval pressure gradient $2.2 \pm 1.1$ vs $8.2 \pm 1.3 \mathrm{~mm} \mathrm{Hg}$ in controls vs $M C D, P<0.001$ ). Dose-response curves to acetylcholine were significantly reduced in MCD-fed rats $(P<0.001)$ as was the responsiveness to methoxamine $(P<0.001)$. Vascular corrosion casts showed a replacement of the regular sinusoidal anatomy by a disorganized pattern with multiple interconnections and vascular extensions. Liver phosphorylated endothelial NO synthase (eNOS)/eNOS and serum nitrite/nitrate were not increased in severe steatosis, whereas liver thromboxane synthase expression, liver endothelin-1 (ET-1) expression and serum andothelin-1 concentration were significantly increased. Severe steatosis induces a haemodynamically significant increase in intrahepatic resistance, which precedes inflammation and fibrogenesis. Both functional (endothelial dysfunction and increased thromboxane and ET-1 synthesis) and structural factors are involved. This phenomenon might significantly contribute to steatosis-related disease.

Laboratory Investigation (2012) 92, 1428-1439; doi:10.1038/labinvest.2012.103; published online 13 August 2012
\end{abstract}

KEYWORDS: endothelial dysfunction; in situ perfusion; intrahepatic resistance; morphological alterations; NAFLD; portal hypertension

Non-alcoholic fatty liver disease (NAFLD) is increasingly recognized as an important source of liver-related morbidity and mortality, taking epidemic proportions because of its intimate link with the metabolic syndrome and its features. ${ }^{1,2}$ Steatosis can be accompanied by signs of inflammation and hepatocellular damage, leading to the definition of nonalcoholic steatohepatitis (NASH). ${ }^{1}$

NASH can lead to progressive fibrosis, and ultimately cirrhosis and its complications, including hepatocellular carcinoma. ${ }^{3}$ NAFLD is also associated with increased

\footnotetext{
${ }^{1}$ Department of Gastroenterology and Hepatology, University Hospital Antwerp, Antwerp, Belgium; ${ }^{2}$ Laboratory of Experimental Medicine and Paediatrics, Division of Gastroenterology, Faculty of Medicine, University of Antwerp, Antwerp, Belgium; ${ }^{3}$ Department of Hepatology, University Hospital Gasthuisberg, Leuven, Belgium; ${ }^{4}$ Department of Hepatology, Ghent University Hospital, Ghent, Belgium; ${ }^{5}$ Department of Morphology, Faculty of Veterinary Medicine, Ghent University, Ghent, Belgium; ${ }^{6}$ ITERA (International Tissue Engineering Research Association) Life Sciences Forum, Lanaken, Belgium; ${ }^{7}$ Genetisch-Diagnostisches Labor, Köln, Germany and ${ }^{8}$ Laboratory of Pathology, Faculty of Medicine, University of Antwerp, Antwerp, Belgium

Correspondence: Dr S Francque, MD, PhD, Department of Gastroenterology and Hepatology, University Hospital Antwerp, Wilrijkstraat 10, Edegem B-2650, Belgium. E-mail: sven.francque@uza.be
}

*These authors share first authorship.

Received 17 October 2011; revised 20 June 2012; accepted 28 June 2012 
morbidity and mortality in case of liver surgery ${ }^{4}$ and with poor graft function in case of a steatotic donor liver, ${ }^{5}$ attributed to impaired liver regeneration. ${ }^{6}$ Furthermore, NAFLD appears to be an independent cardiovascular risk factor $^{7}$ and is also implicated in the pathogenesis of the metabolic syndrome. ${ }^{2}$

The pathogenesis of NAFLD, of its related morbidities and of its progression to NASH remains poorly understood. Reduction in sinusoidal flow and sinusoidal narrowing have been described. ${ }^{8,9}$ We recently reported that portal pressure is significantly elevated in severe NAFLD in a rat model. ${ }^{10}$ This indicates an important increase of the intrahepatic resistance with haemodynamic repercussions in severe steatosis. We also showed that this increase in portal pressure was related to the severity of the steatosis and occurred in the complete absence of fibrosis. Furthermore, we showed that the increase in portal pressure coincides with the development of severe steatosis and precedes necro-inflammatory changes, ${ }^{10}$ leading to the hypothesis that steatosis-related increase in intrahepatic resistance might, via local ischaemia, contribute to the progression of NAFLD to NASH. These findings appeared to be clinically relevant, as we could demonstrate portal hypertension in a group of obese NAFLD patients with severe steatosis but minor degrees of fibrosis. ${ }^{11}$

Although the increase in portal pressure suggests an increase in intrahepatic vascular resistance to blood flow, the latter was not directly assessed. The intrahepatic resistance refers to the resistance in the liver vascular bed to the flow that reaches the liver via the portal vein and can experimentally be assessed, based on Ohm's law, by measuring portal pressure changes when an increasing portal venous flow is applied. The present study therefore aimed at directly studying the intrahepatic resistance and its determinants in a rat model of NAFLD.

\section{MATERIALS AND METHODS Animal Model}

Male Wistar rats (Charles River, Brussels, Belgium) (150-200 g) were fed a methionine-choline-deficient (MCD) diet (ICN Biomedicals SA, Asse, Belgium; $n=30$ ) or a standardized control diet (ICN Biomedicals SA; $n=30$ ). They were allowed unlimited access to their specific food and water, and kept in cages of up to four animals. A MCD diet induces steatosis after 3-4 weeks and is an established model of steatosis and steatohepatitis, with rodent-specific differences in sensitivity. ${ }^{12}$ We previously demonstrated in a detailed analysis of our model that the MCD diet in our male Wistar rats rapidly induces steatosis, which is already almost $100 \%$ at week 3 , whereas signs of inflammation and oxidative stress develop only beyond 4 weeks of MCD diet. ${ }^{10}$

The protocols were approved by the Antwerp University Ethical Committee on Animal Experiments, and the animals received human care and were treated according to the Helsinki declaration, the national guidelines for animal protection and the 'Guide for the Care and Use of Laboratory Animals' (National Institutes of Health, 1985).

\section{Blood and Tissue Sampling}

To avoid any potential influence of manipulation on the measured parameters, five animals of each group were used for sampling of blood and liver tissue without being subjected to any experimental procedure.

After an overnight fast and under anaesthesia (see section Drugs) the animals were weighed and blood samples were taken by puncture of the lateral tail vein. After centrifugation, the supernatant was stored at $-80^{\circ} \mathrm{C}$ until further processing.

The liver was subsequently removed and weighed. A tissue sample of two different liver lobes was fixed in formaldehyde $4 \%$ for histology. Other liver tissue samples were frozen in liquid nitrogen and subsequently stored at $-80^{\circ} \mathrm{C}$ until further processing.

\section{Histology}

After fixation and sectioning, the liver tissue samples were stained with haematoxylin-eosin and Trichrome-Masson, and scored in a blinded way by one single experienced pathologist using the NASH Clinical Research Network Scoring System. ${ }^{13}$ Steatosis was scored as follows: macrovesicular steatosis in $<5 \%$ of the hepatocytes: 0 ; in 5-33\% of hepatocytes: 1 ; $>33-66 \%$ of hepatocytes: 2 ; and $>66 \%$ of hepatocytes: 3 . Lobular inflammation was scored as follows: no foci: $0 ;<2$ foci per $\times 200$ field: $1,2-4$ foci per $\times 200$ field: $2,>4$ foci per $\times 200$ field: 3 . Other histological features that were evaluated include portal inflammation, fibrosis, signs of liver cell injury (hepatocyte ballooning, acidophilic bodies, megamitochondria), glycogenated nuclei and the presence of Mallory's hyaline.

\section{Immunohistochemistry}

Liver sections were stained with rat anti-ED1 monoclonal antibody (Acris Antibodies GmbH, Hiddenhausen, Germany). ED1 is the rat homologue of human CD68 and a marker of tissue macrophages and peripheral blood granulocytes. Liver sections were even so stained with rat anti- $\alpha$ smooth muscle actin (SMA; Acris Antibodies $\mathrm{GmbH}$ ) as a marker for activated stellate cells (which may acquire contractile properties upon activation). Cells were counted in 10 different areas at magnification $\times 20$ and averaged.

\section{Reverse Transcriptase PCR (RT-PCR)}

Total RNA was extracted from stored frozen liver samples using the Absolute RNA Microprep Kit according to the manufacturer's instructions. TaqMan Gene expression assays for three inflammatory cytokines (interleukin-6 (IL-6) (Applied Biosystems, Lennik, Belgium, Gene ID 24498, reference Rn01410330_m1), tumour necrosis factor- $\alpha$ (TNF- $\alpha$ ) (Applied Biosystems, Lennik, Belgium, Gene ID 24835, reference Rn00562055_m1) and IL-1 $\beta$ (IL-1 $\beta$ ) (Applied Biosystems, Lennik, Belgium, Gene ID 24494, reference Rn00580432_m1)) 
were performed on an ABI Prism 7300 sequence detector system (Applied Biosystems) in $25 \mu \mathrm{l}$ reaction volumes containing One Step Universal PCR Master Mix (Applied Biosystems). The parameters for PCR amplification were $48^{\circ} \mathrm{C}$ for $30 \mathrm{~min}, 95^{\circ} \mathrm{C}$ for $10 \mathrm{~min}$, followed by 40 cycles of $95^{\circ} \mathrm{C}$ for $15 \mathrm{~s}$ and $60^{\circ} \mathrm{C}$ for $1 \mathrm{~min}$. $\beta$-actin was used as a housekeeping gene to normalize the results (Applied Biosystems, Lennik, Belgium, Gene ID 81822, reference Rn00667869_m1). The relative mRNA expression of each studied gene was calculated using the $\Delta C_{\mathrm{t}}$ method.

\section{Analysis of Serum Samples}

All samples were analysed on the same day. The following inflammatory cytokines were studied: IL-6 was determined by a $4.5 \mathrm{~h}$ solid phase ELISA according to the manufacturer's instructions (Quantile, R\&D Systems, Minneapolis, MN, USA); TNF- $\alpha$, IL- $1 \beta$ and interferon gamma (IFN- $\gamma$ ) were determined by a $4.5 \mathrm{~h}$ solid phase ELISA according to the manufacturer's instructions (Fluorokine, R\&D Systems). Results are expressed in $\mathrm{pg} / \mathrm{ml}$. C-reactive protein was not included in the analysis, as it is not a reliable marker of acute phase inflammation in rats. ${ }^{14}$

As nitric oxide $(\mathrm{NO})$ is an important vasodilator involved in the pathogenesis of portal hypertension, its potential role was even so studied. ${ }^{15}$ Production of NO by endothelial NO synthase (eNOS) is an important process in the regulation of vascular tone and reflects one of the functions of the endothelium. One way of studying NO production is to assess the degree of systemic NO release by measuring the nitrate/nitrite content in serum samples, which was done with a fluorometric assay (KGE 001, RnD Systems Europe, Abingdon, UK). ${ }^{15}$

Endothelin-1 (ET1) is a potent vasoactive polypeptide mainly produced by endothelium and exerts its activity via endothelin receptor $\mathrm{A}\left(\mathrm{ET}_{\mathrm{A}}\right)$ located on smooth muscle cells and hepatic stellate cells (which contain contractile elements), leading to vasoconstriction. ${ }^{16}$ Binding to endothelin receptor $\mathrm{B}$ $\left(\mathrm{ET}_{\mathrm{B}}\right)$ on endothelial cells might lead to vasodilation via $\mathrm{NO}$ release. ${ }^{16}$ ET-1 upregulation has recently been implicated in the pathogenesis of portal hypertension and the associated increase in intrahepatic resistance. ${ }^{16-18}$ ET-1 was therefore measured in serum using an ELISA technique (Enzo Life Sciences BVBA, Antwerp, Belgium).

\section{Western Blot Analysis}

Aliquots of the protein extraction fractions of liver samples were run on a SDS-polyacrylamide gel and transferred to a nitrocellulose membrane. Equal loading was verified by Ponceau staining. The blots were subsequently probed overnight at $4{ }^{\circ} \mathrm{C}$ with rat anti-eNOS and anti-phosphorylated eNOS (P-eNOS) antibody (Bioconnect, Huissen, The Netherlands), as a decreased eNOS phosphorylation resulting in decreased eNOS activity and hence reduced endothelial NO production is a well characterized mechanism of endothelial dysfunction. ${ }^{19,20}$
As also thromboxane A2 (TXA2; a vasocontrictor prostanoid mainly produced by platelets, but also by endothelial cells) has been implicated in the increased intrahepatic resistance in cirrhosis, ${ }^{21,22}$ TXA2 synthase (TXAS) was even so measured by incubating blots with rat anti-TXAS (Bioconnect).

Endothelin pathways were also assessed by analyzing ET-1, $\mathrm{ET}_{\mathrm{A}}$ and $\mathrm{ET}_{\mathrm{B}}$ expression using rat anti-ET1, $\mathrm{ET}_{\mathrm{A}}$ and $\mathrm{ET}_{\mathrm{B}}$ antibodies (Bioconnect).

Following incubation with secondary antibodies, blots were revealed by chemiluminescence and digital images were taken. Quantitative densitometry values of proteins were normalized to $\beta$-actin. The degree of eNOS phosphorylation was calculated as the ratio between P-eNOS and eNOS normalized densitometry values.

\section{Myeloperoxidase Activity}

Myeloperoxidase (MPO) activity is directly related to the number and activity of myeloid cell infiltrates in the inflamed tissue and can be used to monitor the degree of inflammation. ${ }^{23}$ MPO activity was measured on the frozen liver tissue samples. All liver samples were analysed on the same day. MPO activity was measured according to the method described by Giakoustidis et al. ${ }^{24}$ Briefly, liver tissue homogenates are treated with hexadecyltrimethylammonia to release MPO from the granules in neutrophils, and the supernatant is analysed spectrophotometrically after adding tetramethylbenzidin and $\mathrm{H}_{2} \mathrm{O}_{2}$ by measuring absorption ad $655 \mathrm{~nm}$ for $60 \mathrm{~s}$ at $25^{\circ} \mathrm{C}$. Results are expressed as U MPO/g liver tissue.

\section{In Vivo Haemodynamic Measurements}

MCD-fed $(n=5)$ and control-diet-fed $(n=5)$ rats were subjected to in vivo haemodynamic measurements. After an overnight fast and under anaesthesia (see section Drugs) a tracheal tube (PE 240 ID $1.67 \mathrm{~mm}$ OD $2.42 \mathrm{~mm}$ Intramedic Clay Adams Brand Non-radiopaque Polyethylene Tubing) was inserted by tracheotomy. A $24 \mathrm{G}$ catheter was inserted in the common carotid artery. The abdomen was subsequently opened by median incision. The portal vein was exposed and cannulated with a $24 \mathrm{G}$ catheter under stereomicroscopy. The caudal caval vein was cannulated with a $22 \mathrm{G}$ catheter, which was advanced with the tip into the retrohepatic part of the caudal caval vein. The different catheters were connected to an in-house pressure-monitoring equipment. Common carotid artery pressure (mean arterial blood pressure, $\mathrm{MABP}$ ), pulse rate (PR), portal pressure (PP) and caudal caval vein pressure (CCVP) were measured, and the portocaval pressure gradient (PCPG) was calculated by subtracting the CCVP from the PP.

\section{In Situ Liver Perfusion Studies}

After an overnight fast and under anaesthesia (see section Drugs) in situ perfusion studies were performed using a flowcontrolled system as previously described. ${ }^{15,25}$ After median 
laparatomy, the caudal caval vein was exposed and injected with heparin (1400 U/kg body weight). Subsequently, a ligature was passed around the caudal caval vein. The portal vein was cannulated with a $14 \mathrm{G}$ catheter and the liver perfused with oxygenated Krebs solution at $37^{\circ} \mathrm{C}$ pumped from the reservoir (Masterflex, Vernon Hills, IL, USA) into an overflow chamber via a Pall Ultipor filter (Pall, East Hills, NY, USA). The abdominal aorta and caudal caval vein were cut caudal to the ligature, allowing exsanguination and perfusate efflux. After thoracotomy, the right atrium was cannulated with a PE-240 tube (Portex, Kent, UK). The catheter was advanced into the caudal caval vein up to the hepatic veins outlet. The ligature around the caudal caval vein was closed, forcing the perfusion solution to flow via the catheter in the caudal caval vein and right atrium. The fluid was recovered and a closed circuit was created once the effluent perfusate was clear. This experimental set-up is schematically represented in Figure 1.

The intrahepatic vascular resistance to blood flow was subsequently assessed by measuring flow-pressure response curves based on Ohm's law (pressure $=$ resistance $\times$ flow).

First a constant flow of $35 \mathrm{ml} / \mathrm{min}$ was applied. An ultrasonic flow probe (T201, Transonic, Ithaca, NY, USA) and a pressure gauge were placed in line immediately upstream of the inlet catheter to continuously monitor portal flow and perfusion pressure. A pressure gauge was also connected immediately downstream the outlet catheter to monitor outlet pressure. Criteria of liver viability were the gross appearance of the liver, stable perfusion pressure (starting value $\pm 1 \mathrm{~mm} \mathrm{Hg})$ and a stable buffer $\mathrm{pH}(7.4 \pm 0.1)$. The preparation was allowed to stabilize for $30 \mathrm{~min}$ before further experimentation.

The flow probe and pressure transducers were connected to a Powerlab data acquisition system with Chart 5 v5.4.1 software (ADInstruments, Oxford, UK) for continuous recording.

Flow-pressure curves $(5 \mathrm{ml} / \mathrm{min}$ increase every $5 \mathrm{~min}$ ) were subsequently performed in control rats $(n=5)$ and in rats with steatosis $(n=5) .{ }^{15}$

The intrahepatic vascular tone was further assessed by the evaluation of endothelial function in controls $(n=5)$ and in rats with steatosis $(n=5)$. The endothelial function was evaluated by performing concentration-effect curves to cumulative doses of acetylcholine (ACh, an endotheliumdependent vasodilator; $10^{-7}$ to $10^{-5} \mathrm{~mol} / \mathrm{l}$, one log increase every $1.5 \mathrm{~min}$ ) after a 5 -min precontraction with methoxamine, an $\alpha 1$-adrenergic agonist at a concentration of $10^{-4} \mathrm{~mol} / \mathrm{l}$. The results were expressed as percentage of change (\%) of the portal perfusion pressure (at a constant rate of $30 \mathrm{ml} / \mathrm{min}$ ) compared with the baseline value obtained before administration of ACh. ${ }^{15}$

Finally, the intrahepatic tone was assessed by the evaluation of the responsiveness to methoxamine ( $n=5$ in controls and rats with steatosis, respectively). This was tested by performing dose-response curves to cumulative doses of methoxamine $\left(10^{-6}\right.$ to $10^{-4} \mathrm{~mol} / \mathrm{l}$, one log increase every

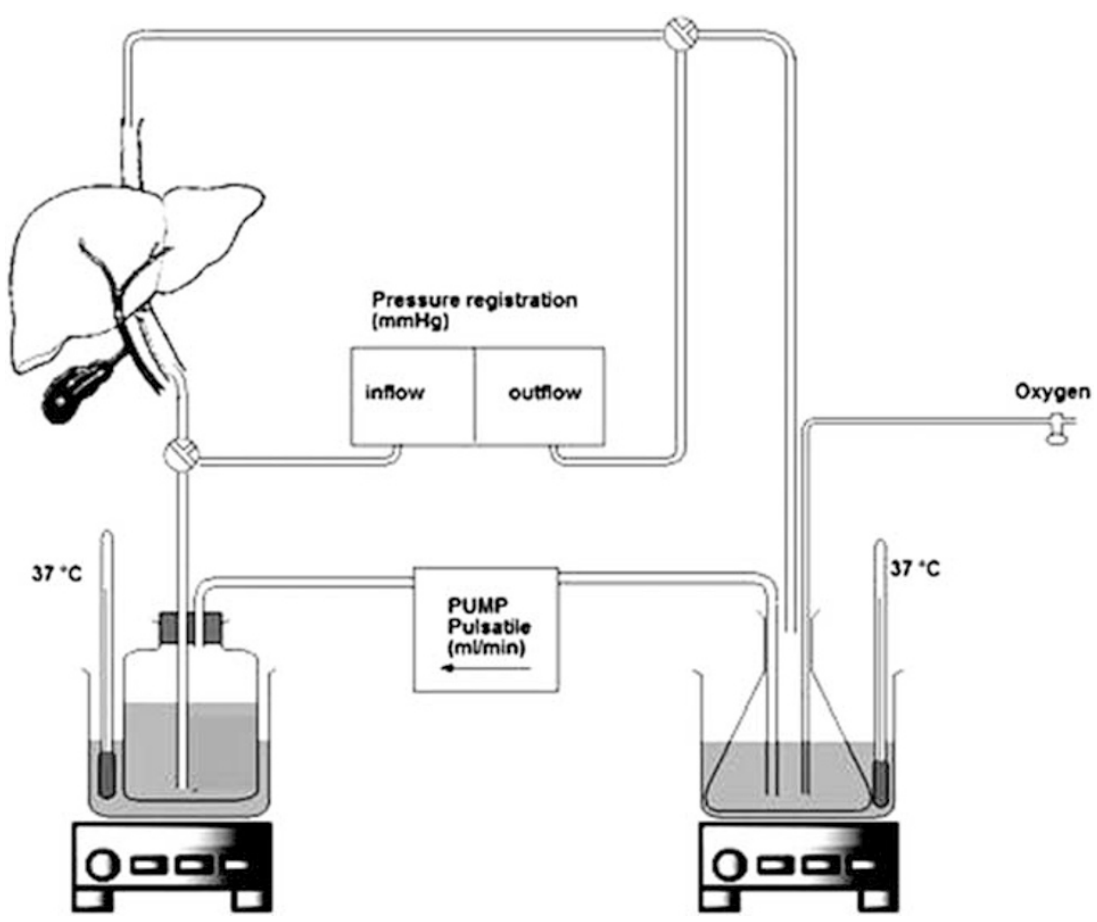

Figure 1 Schematic representation of the in situ perfusion experimental set-up. The portal vein and right atrium are cannulated, the inferior caval vein, hepatic artery and bile duct ligated. Pressure is measured in the portal vein and in the outflow tract. A calibrated flow is applied by a pump in a closed circuit. 
$5 \mathrm{~min})$. The results were expressed as the absolute change (delta change in $\mathrm{mm} \mathrm{Hg}$ ) of the portal perfusion pressure (at a constant rate of $30 \mathrm{ml} / \mathrm{min}$ ) compared with the baseline value obtained before administration of methoxamine. ${ }^{15}$

\section{Vascular Corrosion Casts}

Vascular corrosion casting was performed as previously described. ${ }^{26}$ After overnight fasting animals fed the MCD diet $(n=5)$ or the control diet $(n=5)$ were killed by means of an intraperitoneal injection of an overdose of a solution containing $0.8 \mathrm{ml}$ ketamin (Anesketin, Eurovet, Heusden-Zolder, Belgium) and $0.2 \mathrm{ml}$ xylezine (Xyl-M, VMD, Arendonk, Belgium). They subsequently underwent a median laparotomy. A $26 \mathrm{G}$ catheter was inserted into the ileocolic vein. Twenty millilitre of freshly prepared Batson's no. 17 solution (Brunschwig Chemie, Amsterdam, The Netherlands) was subsequently injected using 1-ml syringes. Animal bodies were immersed for $30 \mathrm{~min}$ in tepid water during polymerization and macerated overnight in $25 \%$ potassium hydroxide. The vascular corrosion casts were gently rinsed with streaming water for $3 \mathrm{~h}$. Samples of the casts were then mounted on a metal stub, coated with platinum (Jeol Auto Fine Coater, JFC 1300, Jeol, Zaventem, Belgium) and examined systematically with a scanning electron microscope (Jeol JSM 5600 LV, Jeol).

\section{Drugs}

Animals were anaesthetized with Nembutal, Ceva Santé Animale, Brussels, Belgium: Natrii Pentobarbitalum $60 \mathrm{mg} /$ $1 \mathrm{ml}, 0.05 \mathrm{ml} / 100 \mathrm{~g}$ body weight, $30 \mathrm{mg} / \mathrm{kg}$ body weight intraperitoneally. The Krebs-Ringer solution has the following composition: $\mathrm{KCl} 4.75 \mathrm{mM}, \mathrm{MgSO}_{4} .7 \mathrm{H}_{2} \mathrm{O} 1.2 \mathrm{mM}, \mathrm{KH}_{2} \mathrm{PO}_{4}$ $1.2 \mathrm{mM}, \mathrm{CaCl}_{2} .2 \mathrm{H}_{2} \mathrm{O} \quad 2.5 \mathrm{mM}$, CaEDTA $0.03 \mathrm{mM}, \mathrm{NaCl}$ $118.5 \mathrm{mM}, \mathrm{NaHCO}_{3} 25 \mathrm{mM}$, glucose $10 \mathrm{mM} ; \mathrm{pH}=7.4$. The $50 \mathrm{mM} \mathrm{K}^{+}$Krebs-Ringer solution has the following composition: $\mathrm{KCl} 48.8 \mathrm{mM}, \mathrm{MgSO}_{4} .7 \mathrm{H}_{2} \mathrm{O} 1.2 \mathrm{mM}, \mathrm{KH}_{2} \mathrm{PO}_{4}$ $1.2 \mathrm{mM}, \mathrm{CaCl}_{2} .2 \mathrm{H}_{2} \mathrm{O} \quad 2.5 \mathrm{mM}$, CaEDTA $0.03 \mathrm{mM}$, $\mathrm{NaCl}$ $118.5 \mathrm{mM}, \mathrm{NaHCO}_{3} 25 \mathrm{mM}$, glucose $10 \mathrm{mM} ; \mathrm{pH}=7.4$. Methoxamine and ACh were purchased from Sigma-Aldrich Chemie Gmbh, Steinheim, Germany. Methoxamine and ACh were dissolved in aqua destillata, and solutions were freshly prepared on the day the experiments were performed.

\section{Statistics}

The data are presented as mean \pm s.d. Basic haemodynamic characteristics, serum concentrations of cytokines and liver tissue MPO were compared using independent samples $t$-test using SPPS 15.0 for Windows. The slopes of the flow-perfusion curves were calculated by linear regression analysis. The flow-perfusion curves and the dose-response curves were analysed with one-way ANOVA between groups (controls vs steatosis) and subsequently by pairwise multiple comparison testing (Tukey's test).
Table 1 Weight and haemodynamic characteristics of control rats vs rats with steatosis

\begin{tabular}{lccc}
\hline & Controls $(n=5)$ & Steatosis $(n=5)$ & $P$-value \\
\hline Body weight $(\mathrm{g})$ & $187.0 \pm 7.8$ & $131.0 \pm 8.9$ & $<0.001^{*}$ \\
Liver weight $(\mathrm{g})$ & $7.6 \pm 0.4$ & $6.61 \pm 0.8$ & $0.037^{*}$ \\
Liver body weight ratio & $0.0406 \pm 0.0011$ & $0.0505 \pm 0.0054$ & 0.004 \\
MABP (mm Hg) & $123.8 \pm 4.0$ & $99.4 \pm 7.1$ & $<0.001^{*}$ \\
PR (bpm) & $207.0 \pm 35.8$ & $212.0 \pm 22.24$ & 0.858 \\
PP (mm Hg) & $2.6 \pm 0.9$ & $8.8 \pm 1.3$ & $<0.001^{*}$ \\
CCVP (mm Hg) & $0.4 \pm 0.5$ & $0.6 \pm 0.5$ & 0.580 \\
PCPG (mm Hg) & $2.2 \pm 1.1$ & $8.2 \pm 1.3$ & $<0.001^{*}$ \\
\end{tabular}

Abbreviations: MABP, mean arterial blood pressure; PR, pulse rate; PP, portal pressure; CCVP, caudal caval vein pressure; PCPG, portocaval pressure gradient.

Body weight, liver weight, the ratio between liver and body weight, MABP, PR, PP, CCVP and PCPG are shown for rats receiving the control diet or the methionine-choline-deficient diet for 4 weeks, respectively. The results are expressed as mean \pm s.d. The $P$-values of the comparison between rats on the control diet and rats on the MCD diet are listed (independent samples $t$-test). A $P$-value $<0.05$ is considered statistically significant $(*)$.

\section{RESULTS}

\section{Liver Volume and Histology}

After 4 weeks of diet, the animals receiving the MCD diet developed a severe steatosis, resulting in marked hepatomegaly: the liver/body weight ratio was significantly increased compared with the control animals (Table 1). The increase in liver volume and liver/body weight ratio corresponded with histology, confirming a severe ( $>60 \%$ of the hepatocytes) steatosis in all of the treated animals, whereas the control animals did not show any significant accumulation of fat (Figure 2a and b). Besides slight lobular inflammation (score 1) in one out of five, other features of NASH were absent in the MCD-diet-fed group. Fibrosis, as assessed by TrichromeMasson stain, was completely absent (Figure $2 \mathrm{~b}$ ). There were no significant differences between the two liver lobes. All these elements confirm the model of severe steatosis without marked inflammation or fibrosis after 4 weeks of diet in rats.

\section{Immunohistochemistry}

The mean number of ED1-positive cells per $\times 40$ field was $9.6 \pm 2.5$ in the rats with steatosis $v s 11.5 \pm 1.8$ in controls, $P=0.265$. The mean number of $\alpha$ SMA-positive cells per $\times 20$ field (excluding the vessel wall of portal tract vessels or centrolobular veins) was $0.3 \pm 0.1$ in rats with steatosis $v s$ $0.2 \pm 0.1$ in controls, $P=0.364$ ). Representative slides are shown in Figure 3a-d.

\section{Inflammatory Cytokines}

The serum concentrations and RT-PCR results of IFN- $\gamma$, TNF- $\alpha$, IL- $1 \beta$ and IL- 6 are listed in Table 2 . No significant 

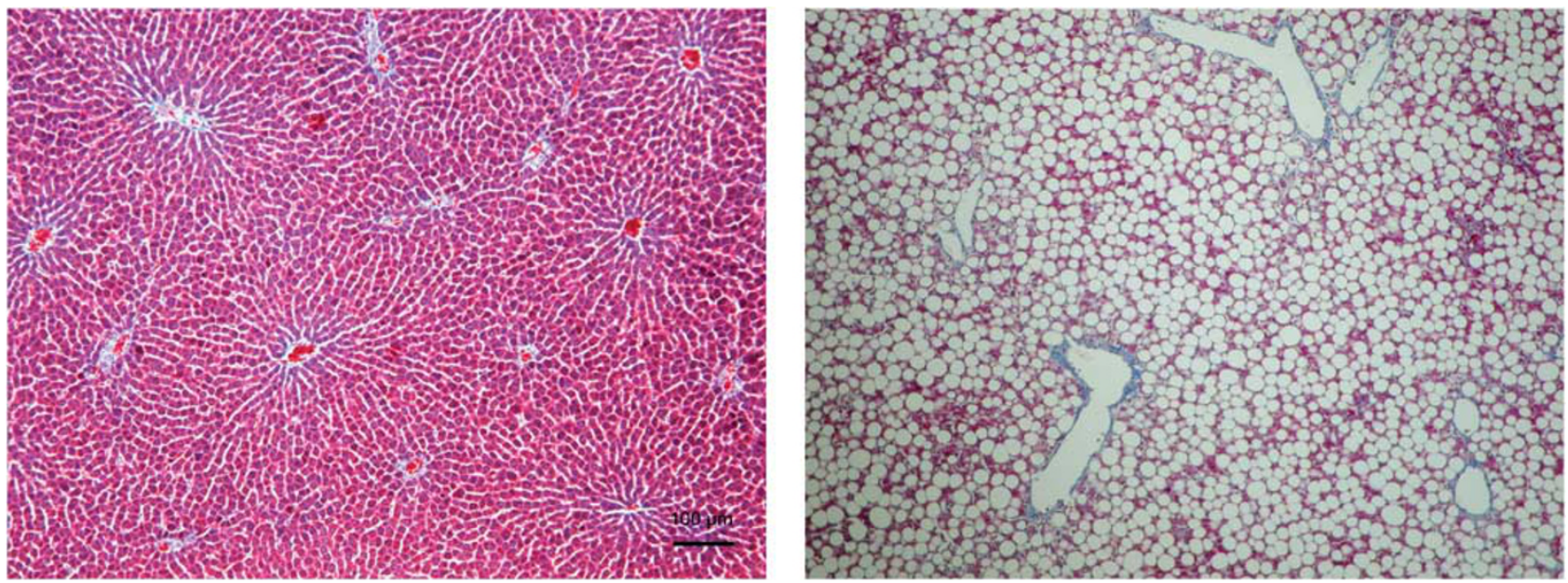

Figure 2 (a) Histological section (Trichrome-Masson stain, original magnification $\times 20$ ) of the liver of a rat fed the control diet. There are no abnormalities. (b) Histological section (Trichrome-Masson stain, original magnification $\times 20$ ) of the liver of a rat fed the MCD diet. There is maximal steatosis but no portal or lobular inflammation, no ballooning and no significant fibrosis.
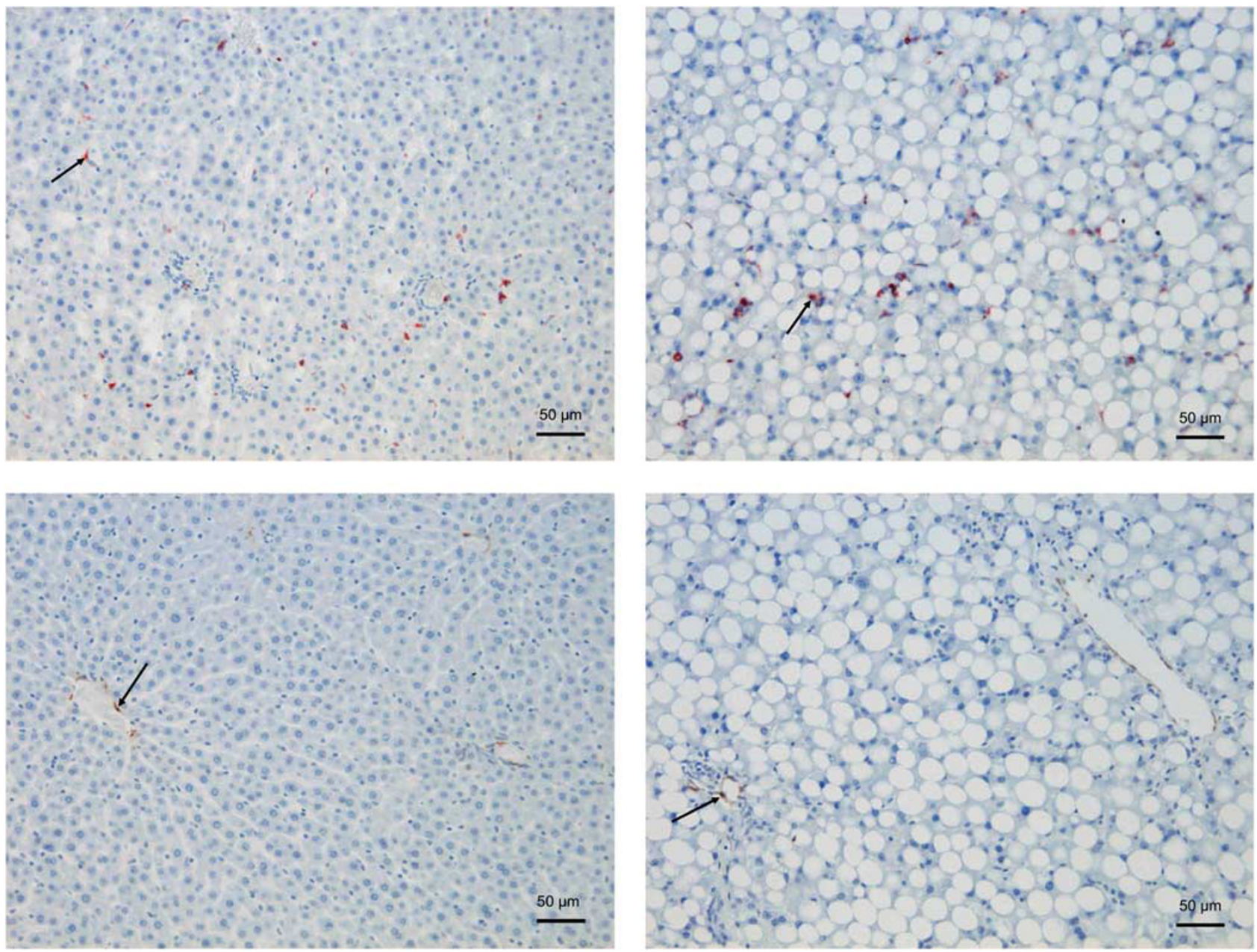

Figure 3 ED1 immunohistochemical stain of control rats (a) and rats with steatosis (b), and $\alpha$-smooth muscle actin ( $\alpha$ SMA) immunohistochemical stain in control rats $(\mathbf{c})$ and rats with steatosis (d), original magnification $\times 20$. ED1-positive cells (macrophages) and $\alpha$ SMA-positive cells (smooth muscle cells in the vessel wall and activated stellate cells) are indicated with an arrow. 
Table 2 Serum levels and liver mRNA levels (RT-PCR) of inflammatory cytokines and liver MPO activity in control animals vs animals with steatosis

\begin{tabular}{lccc}
\hline & Controls $(n=5)$ & Steatosis $(n=5)$ & $P$-value \\
\hline Serum IFN- $\gamma(\mathrm{pg} / \mathrm{ml})$ & $51.12 \pm 40.63$ & $37.58 \pm 15.04$ & 0.505 \\
Serum TNF- $\alpha(\mathrm{pg} / \mathrm{ml})$ & $14.47 \pm 4.85$ & $21.20 \pm 8.07$ & 0.245 \\
Serum IL-1 $\beta(\mathrm{pg} / \mathrm{ml})$ & $36.88 \pm 14.04$ & $49.72 \pm 17.01$ & 0.229 \\
Serum IL-6 $(\mathrm{pg} / \mathrm{ml})$ & $29.13 \pm 12.63$ & $29.42 \pm 33.52$ & 0.986 \\
$\Delta C_{\mathrm{t}}$ TNF- $\alpha$ & $15.350 \pm 0.712$ & $15.488 \pm 0.351$ & 0.708 \\
$\Delta C_{\mathrm{t}}$ IL-1 $\beta$ & $7.878 \pm 1.023$ & $7.816 \pm 0.500$ & 0.906 \\
$\Delta C_{\mathrm{t}}$ IL-6 & $16.695 \pm 0.682$ & $17.178 \pm 0.608$ & 0.298 \\
Liver MPO $(\mathrm{U} / \mathrm{g}$ liver tissue $)$ & $0.55 \pm 0.23$ & $0.91 \pm 0.64$ & 0.278 \\
\hline
\end{tabular}

Abbreviations: IFN- $\gamma$, interferon-gamma; TNF- $\alpha$, tumour necrosis factor- $\alpha$; IL-1 $\beta$, interleukin-1 $\beta$; IL-6, interleukin-6; MPO, myeloperoxidase.

The mean values \pm s.d. of serum levels and liver tissue mRNA (expressed by $\Delta C_{\mathrm{t}}$ values) of IFN- $\gamma, \mathrm{TNF}-\alpha, \mathrm{IL}-1 \beta$ and IL- 6 , as well as liver MPO activity are shown for control rats and rats with steatosis, respectively. The $P$-values of the comparison between rats on the control diet and rats on the methionine-choline-deficient diet are listed (independent samples $t$-test). A $P$-value $<0.05$ is considered statistically significant $(*)$.

differences were noted between rats fed the control $v s$ the MCD diet (independent samples $t$-test).

\section{MPO Activity}

The MPO activity is shown in Table 2. No significant differences were noted between rats fed the control $v s$ the MCD diet (independent samples $t$-test).

\section{In Vivo Haemodynamic Measurements}

In animals with steatosis, absolute PP (and PCPG) were markedly elevated compared with control animals, and the difference was highly significant (independent samples $t$-test) (Table 1).

In the steatotic animals, MABP was significantly lower compared with the control group, whereas PR did not change significantly (independent samples $t$-test; Table 1 ).

\section{In Situ Perfusion Experiments}

\section{Total intrahepatic resistance}

Rats fed the MCD diet for 4 weeks showed significantly increased perfusion pressures with increasing flow compared with rats fed the control diet, and hence a significantly increased intrahepatic resistance (Ohm's law; Figure 4). Slope values were significantly different: $0.1636 \pm 0.0605 \mathrm{~mm}$ $\mathrm{Hg} / \mathrm{ml} / \mathrm{min}$ in controls vs $0.7270 \pm 0.0408 \mathrm{~mm} \mathrm{Hg} / \mathrm{ml} / \mathrm{min}$ in rats with steatosis $(P<0.001$, linear regression). Pairwise multiple comparisons (Tukey's tests) showed significant differences between control rats and rats with steatosis for all different flows applied: perfusion flow $30 \mathrm{ml} / \mathrm{min}$ : $5.54 \pm 1.07$ vs $15.80 \pm 0.57 \mathrm{~mm} \mathrm{Hg} ; 35 \mathrm{ml} / \mathrm{min}: 6.06 \pm 1.49$ vs $18.54 \pm 1.17 \mathrm{~mm} \mathrm{Hg} ; 40 \mathrm{ml} / \mathrm{min}: 6.86 \pm 1.52$ vs $22.88 \pm$

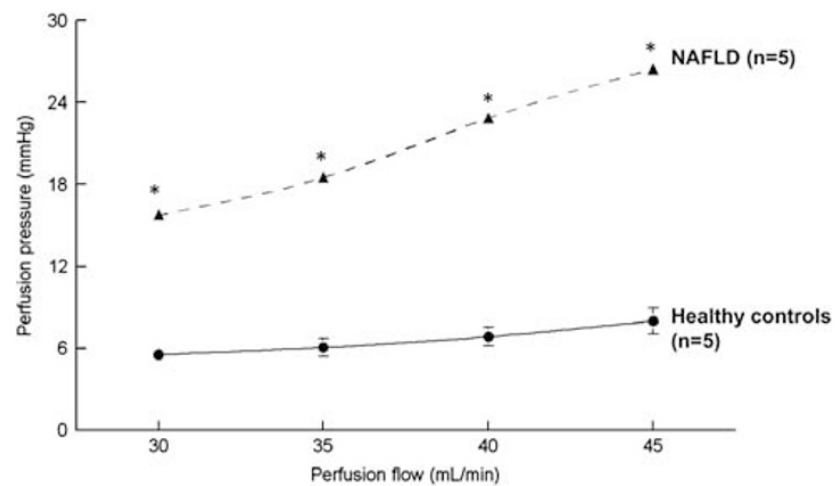

Figure 4 Flow-pressure curves for rats fed the control diet $(\bullet)$ vs rats fed the MCD diet $(\mathbf{\Delta})$. The portal perfusion pressures are significantly elevated in rats with steatosis compared with controls ${ }^{*} P<0.0001$ at comparative flows). Slope values are even so significantly different $(P<0.0001$, linear regression).

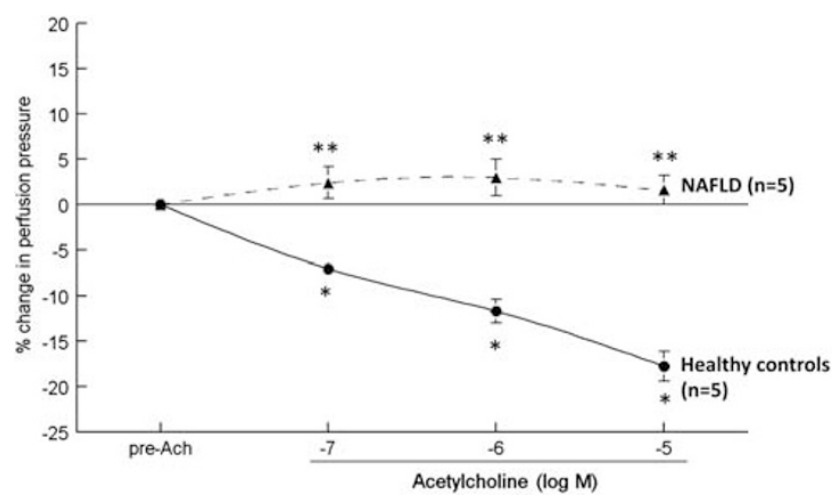

Figure 5 Dose-response curves of portal perfusion pressure (expressed as $\%$ of change from baseline) to increasing doses of acetylcholine $\left(10^{-7}\right.$ to $10^{-5} \mathrm{~mol} / \mathrm{l}$ ) after methoxamine pre-contraction of control rats $(\bullet)$ and rats with steatosis $(\mathbf{\Lambda})$, demonstrating marked endothelial dysfunction in rats with steatosis $\left({ }^{*} P<0.001\right.$ for all doses vs each other within control rats, ${ }^{* *} P<0.001$ for controls $v s$ rats with steatosis at comparative doses).

$1.16 \mathrm{~mm} \mathrm{Hg} ; 45 \mathrm{ml} / \mathrm{min}: 8.00 \pm 2.12$ vs $26.47 \pm 1.03 \mathrm{~mm} \mathrm{Hg}$; all $P<0.001)$.

\section{Endothelial function}

In control animals, cumulative doses of ACh caused an incremental and significant $(P<0.001$, one-way ANOVA within group) vasorelaxation, indicating normal endothelial function. In rats with steatosis, there was virtually no relaxation upon administration of ACh $(P=0.818$, one-way ANOVA within group; Figure 5). The curves were significantly different between control rats and rats with steatosis $(P<0.001$, one-way ANOVA between groups). Pairwise multiple comparison (Tukey's test) showed significant differences between control animals and rats with steatosis for each dose of ACh: ACh $10^{-7} \mathrm{~mol} / \mathrm{l}:-7.04 \pm 1.59 \%$ in controls vs $2.38 \pm 3.93 \%$ in steatosis; ACh $10^{-6}$ : $-11.70 \pm$ 


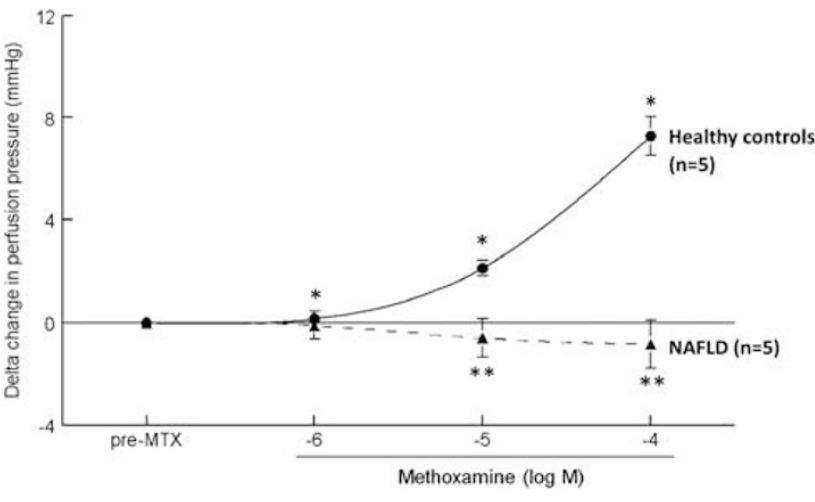

Figure 6 Dose-response curves of portal perfusion pressure (expressed as delta change in $\mathrm{mm} \mathrm{Hg}$ from baseline) to increasing doses of methoxamine $\left(10^{-6}\right.$ to $\left.10^{-4} \mathrm{~mol} / \mathrm{l}\right)$ of control rats $(\bullet)$ and rats with steatosis $(\mathbf{\Lambda})$, demonstrating marked hyporesponsiveness in rats with steatosis $\left({ }^{*} P<0.001\right.$ for all doses vs each other within control rats, ${ }^{*} P<0.001$ for controls vs rats with steatosis at comparative doses).
2.90 vs $2.94 \pm 4.52 \%$; ACh $10^{-5}$ : $-17.78 \pm 3.68$ vs $1.58 \pm$ $3.64 \%$; all $P<0.001$.

\section{Intrahepatic response to methoxamine}

In control animals, cumulative doses of methoxamine caused an incremental and significant $(P=0.002$, one-way ANOVA within group) increase in portal perfusion pressure indicative of a vasoconstrictor response. In rats with steatosis, there was virtually no change in portal perfusion pressure upon administration of methoxamine $(P=0.788$, one-way ANOVA within group) (Figure 6). The curves were significantly different between control rats and rats with steatosis $(P<0.001$, one-way ANOVA between groups). Pairwise multiple comparison (Tukey's test) showed significant differences between control animals and rats with steatosis, respectively, for higher dose of methoxamine: methoxamine $10^{-6} \mathrm{~mol} / \mathrm{l}: 0.16 \pm 0.16$ vs $-0.10 \pm 1.21 \%(P=0.756)$;
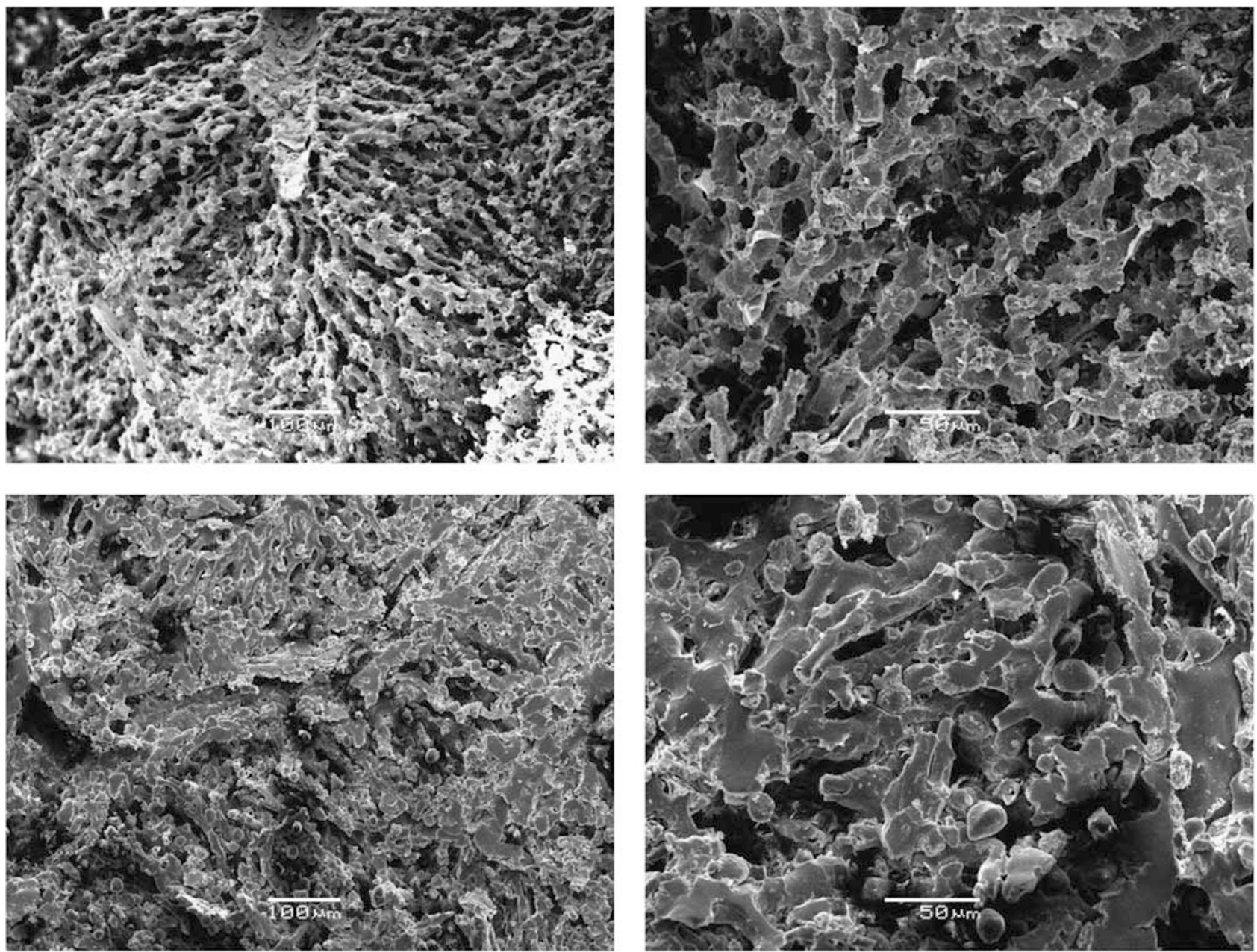

Figure 7 Representative scanning electron microscopic images of vascular corrosion casts of normal livers and livers with steatosis. (a) A normal liver (original magnification $\times 150$ ) showing a regular trabecular pattern and honeycomb appearance. (b) Larger magnification $(\times 400)$ of a normal liver. (c) A liver with severe steatosis showing a denser and markedly disorganized pattern with loss of the classical trabecular ordering and with the presence of blebs (arrow; original magnification $\times 150)$. (d) Larger magnification $(\times 400)$ of a liver with steatosis. 
Table 3 Parameters of NO, TXA2 and ET-1 in control animals vs animals with steatosis

\begin{tabular}{lccc}
\hline & Controls $(n=5)$ & Steatosis $(n=5)$ & $P$-value \\
\hline Serum NO $(\mu \mathrm{mol} / \mathrm{l})$ & $26.76 \pm 5.34$ & $32.04 \pm 6.34$ & 0.236 \\
Serum ET-1 $(\mathrm{pg} / \mathrm{ml})$ & $14.39 \pm 2.03$ & $18.48 \pm 1.36$ & $0.006^{*}$ \\
WB P-eNOS & $0.0066 \pm 0.0018$ & $0.0062 \pm 0.0011$ & 0.684 \\
WB eNOS & $0.3080 \pm 0.1086$ & $0.2743 \pm 0.0558$ & 0.600 \\
WB P-eNOS/eNOS & $0.0200 \pm 0.0055$ & $0.0245 \pm 0.0053$ & 0.281 \\
WB TXAS & $0.0520 \pm 0.0087$ & $0.0713 \pm 0.0083$ & $0.012^{*}$ \\
WB ET-1 & $0.0759 \pm 0.0150$ & $0.0976 \pm 0.0068$ & $0.043^{*}$ \\
WB ETA & $0.0397 \pm 0.0156$ & $0.0299 \pm 0.0172$ & 0.372 \\
WB ETB & $0.0278 \pm 0.0182$ & $0.0232 \pm 0.0124$ & 0.653 \\
\hline
\end{tabular}

Abbreviations: NO, nitric oxide; ET-1, endothelin-1; WB, western blot; P-eNOS, phophorylated endothelial NO synthase; TXAS, thromboxane A2 synthase; $\mathrm{ET}_{\mathrm{A}}$, endothelin receptor $\mathrm{A} ; \mathrm{ET}_{\mathrm{B}}$, endothelin receptor $\mathrm{B}$.

The mean values \pm s.d. of serum levels of $N O$ and $E T-1$, and of liver tissue. WB-normalized densitometry values for P-eNOS, NOS, TXAS, ET-1, ET $\mathrm{A}_{\mathrm{A}}$ and $\mathrm{ET}_{\mathrm{B}}$, and the ratio of P-eNOS/NOS WB densitometry values are shown for control rats and rats with steatosis, respectively. The $P$-values of the comparison between rats on the control diet and rats on the methionine-cholinedeficient diet are listed (independent samples $t$-test). A $P$-value $<0.05$ is considered statistically significant $(*)$.

methoxamine $10^{-5}: 2.14 \pm 0.70$ vs $-0.60 \pm 1.67 \%(P<0.001)$; methoxamine $10^{-4}: 7.28 \pm 1.69$ vs $-0.84 \pm 2.12 \%(P<0.001)$.

\section{Vascular Corrosion Casts}

Scanning electron microscopy of the livers of the rats fed the MCD diet revealed marked microvascular changes in comparison with the livers of the rats fed the control diet (Figure 7). Casts of the control livers showed normal filling of the sinusoids with a regular trabecular pattern between the parenchymal trabeculae, creating a classical honeycomb appearance with regular ramifications (Figure $7 \mathrm{a}$ and $\mathrm{b}$ ). In the livers with steatosis, however, the sinusoids looked compressed and the network was markedly more dense and disorganized with loss of the regular trabecular pattern (Figure $7 \mathrm{c}$ and $\mathrm{d}$ ). The vessels also presented numerous rounded blind-ending extensions (blebs; Figure $7 \mathrm{c}$ and $d$ ).

\section{Vasoactive Mediators}

Western blot densitometry values for P-eNOS and eNOS are shown in Table 3. The P-eNOS/eNOS ratio is shown in Table 3 and Figure 8a. The total NO concentration in serum is also listed in Table 3. Although P-eNOS and total eNOS expression tended to be lower in rats with steatosis, no statistically significant differences could be observed between controls and rats with steatosis.

Western blot densitometry values for TXAS are shown in Figure $8 \mathrm{~b}$ and Table 3 . The TXAS blot shows a double band, of which the upper one was identified as TXAS based on previous experiments in rat aorta. Expression of TXAS is significantly higher in rat livers with steatosis compared with livers of control rats.

Western blot densitometry values for $\mathrm{ET}-1, \mathrm{ET}_{\mathrm{A}}$ and $\mathrm{ET}_{\mathrm{B}}$ are shown in Table 3 and Figure 8c (ET-1 only). ET-1 concentrations in serum are also listed in Table 3. Endothelin receptor expressions are not different between control rats and rats with steatosis, whereas ET-1 expression in liver tissue, as well as ET-1 concentration in serum, are significantly elevated in case of steatosis.

\section{DISCUSSION}

In the present study, we show that severe steatosis is associated with an increased portal pressure, caused by a significant increase in intrahepatic resistance. The increase in intrahepatic resistance is related to a marked endothelial dysfunction. The response to vasoconstrictors is reduced. A role for inflammation and oxidative stress in the alterations of the intrahepatic resistance could not be demonstrated. TXA2 and ET- 1 are increased, whereas no alterations in NO could be demonstrated, pointing towards an increase in vasoconstrictors and a vasoconstrictor/vasodilator imbalance in case of steatosis. Vascular corrosion casts showed marked changes in sinusoidal morphology, with a replacement of the normal regular orientation by a disorganized pattern.

Steatosis is known to be associated with sinusoidal narrowing and a reduction in sinusoidal flow. ${ }^{8,27}$ We recently showed that severe steatosis is associated with a significant increase in portal pressure in the absence of detectable inflammation and of fibrosis. ${ }^{10}$ These findings suggest that severe steatosis causes a haemodynamically significant increase of the intrahepatic resistance, but the latter was, to date, not directly assessed. In the present study, we could confirm our hypothesis and clearly prove that intrahepatic resistance is increased in severe steatosis by direct measurement of the total intrahepatic resistance in an in situ perfusion model. The observed changes are marked and the differences between control rats and rats with steatosis are highly significant. The concomitant significant increase in portal pressure reproducing our earlier findings, illustrates that this increase in intrahepatic resistance is of major haemodynamic impact.

Previous experiments showed that the increase in portal pressure observed with severe steatosis precedes necroinflammatory changes that only appear when the increase in portal pressure is fully established. ${ }^{10}$ In the present study, no significant inflammation, as assessed by various histological and biochemical markers, and liver tissue gene expression studies, could be demonstrated, which is in line with previous observations in the same model. We can therefore reliably assume that, in agreement with what was previously observed for the increase in the portal pressure, the observed increase in intrahepatic resistance is also preceding the necroinflammatory changes. On the basis of these observations, it can be hypothesized that intrahepatic fat accumulation by itself initiates a significant increase in 


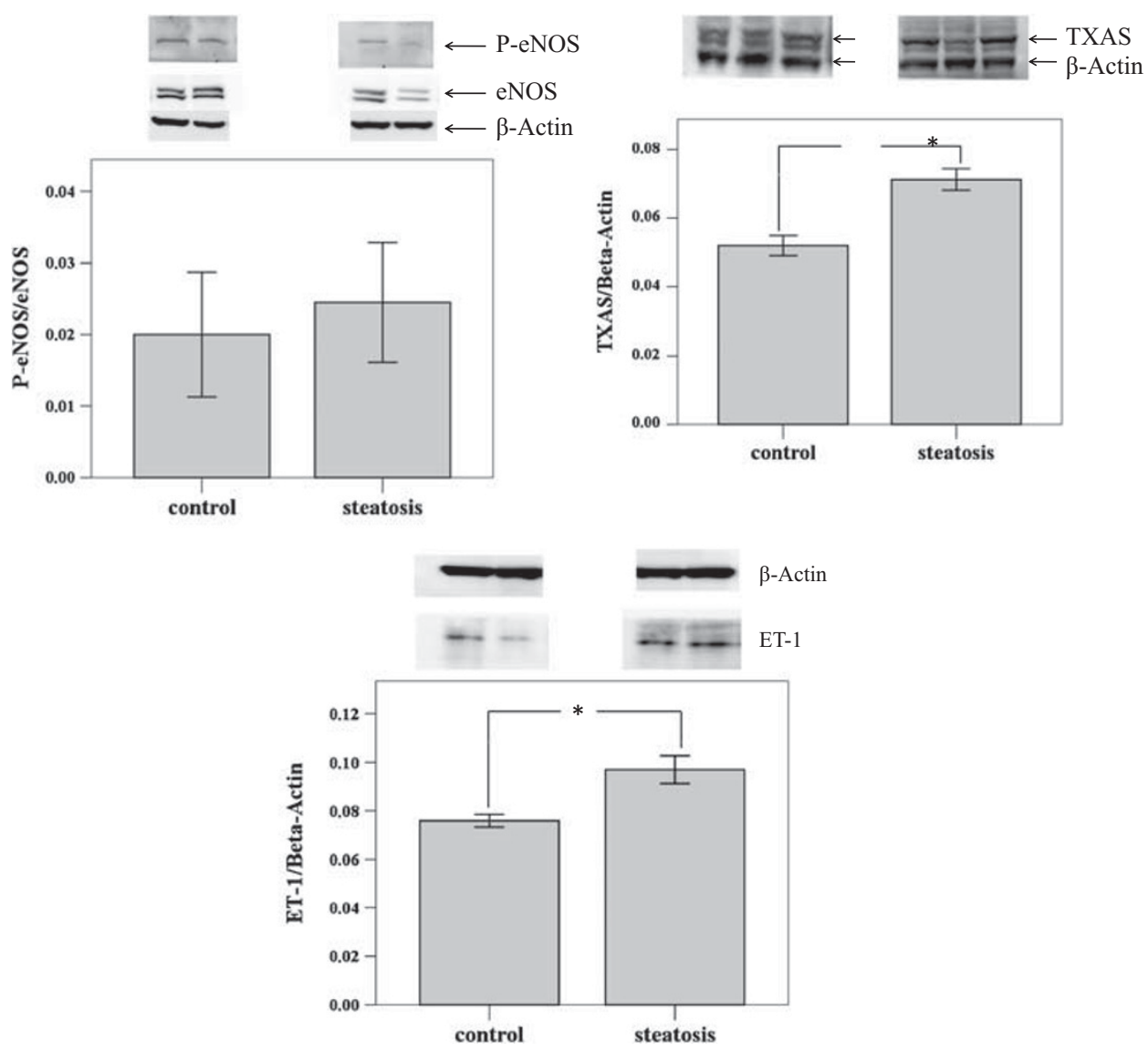

Figure 8 Representative blots and densitometry histograms of livers of control rats and rats with severe steatosis for P-eNOS/eNOS (a), TXAS (b) and ET-1 (c). P-eNOS, phosphorylated endothelial nitric oxide synthase; TXAS, thromboxane A2 synthase; ET-1, endothelin-1; * statistically significant difference between control rats and rats with steatosis ( $P$-value $<0.05)$. The TXAS blot shows a double band, of which the upper one was identified as TXAS based on previous experiments in rat aorta.

intrahepatic resistance that subsequently impairs liver blood flow causing intralobular ischaemia, which in turn might trigger processes of cell damage and inflammation. This mechanism might therefore be an important contributor for the progression from steatosis to steatohepatitis. This hypothesis is also in line with the predominantly centrolobular localization of NASH features. ${ }^{28}$

Intrahepatic resistance is build up by static, structural factors and dynamic factors, the latter being regulated mainly by the interaction between endothelial cells and sinusoidal lining cells, especially stellate cells. ${ }^{29}$ The dynamic factors were studied in the in situ perfusion setting. A first factor that could be identified is the impaired endothelial function. The intact endothelium has a crucial role in vascular tone, as most of the endogenous vasodilator and vasoconstrictor substances act through mechanisms involving the endothelial cell. ${ }^{30,31}$ Endothelial dysfunction, demonstrated by a reduced vasodilatory response to the vasodilator $\mathrm{ACh}$, is known to be present in cirrhosis and is believed to contribute to the cirrhosis-associated portal hypertension. ${ }^{29,31}$ Peripheral endothelial dysfunction is known to be present in patients with the metabolic syndrome and is supposed to contribute to the increased cardiovascular risk associated with this condition. ${ }^{32}$ Endothelial dysfunction is also linked to insulin resistance, a key factor in the pathogenesis of NASH. ${ }^{33,34}$ Recently, Pasarin $e t a l^{35}$ reported reduced response to insulin as a marker of early intrahepatic endothelial dysfunction in rats fed a cafeteria diet for a few days. In this model, histological signs of NAFLD were very mild and portal pressure was not increased. Endothelial dysfunction seems therefore to be an early event in the development of alterations in intrahepatic resistance. Compared with the data of Pasarin et $a l,{ }^{35}$ endothelial dysfunction was clearly more marked in our model, in which histological and haemodynamic alterations are even so much more pronounced.

Another factor contributing to the increase in intrahepatic resistance in cirrhosis is the hyperresponsiveness to vasoconstrictors such as methoxamine. ${ }^{15}$ In the setting of severe steatosis, however, the response to methoxamine is reduced compared with controls. This implies that the mechanisms of increased intrahepatic resistance in steatosis are different compared with cirrhosis, and cannot be attributed to hyperresponsiveness to $\alpha$-adrenergic stimulation. Reduced intrahepatic response to methoxamine has been described in cirrhosis, but in the context of exposure to lipopolysaccharides (as a model of sepsis) via a Kupffer cell-mediated mechanism. ${ }^{36}$ 
Several vasoactive substances have been implicated in the dynamic component of the increased intraheptic resistance in cirrhosis. ${ }^{29} \mathrm{~A}$ reduction in NO production by the endothelium is considered to be a main mechanism. ${ }^{15,19,20}$ We could, however, not find any argument for an alteration of NO production in rats with severe steatosis. Serum NO concentrations were comparable between control rats and rats with steatosis, but might not be an adequate marker for intrahepatic changes. Studies of liver eNOS and P-eNOS protein expression were even so not significantly different between control rats and steatosis, more reliably reflecting the absence of an alteration of NO synthesis as a main contributor to the observed increased intrahepatic resistance, at least in the MCD model.

TXA2, a vasoconstrictor prostanoid derived from arachidonic acid by cyclooxygenase and TXAS, and exerting its action via a receptor on smooth muscle cells and hepatic stellate cells, has also been implicated in the pathogenesis of the increased intrahepatic resistance in cirrhosis. ${ }^{21,22}$ Increase in TXA2 production and cyclooxygenase overexpression have been demonstrated in perfusion models in rats. ${ }^{37,38}$ The increase in TXAS points towards an increase in TXA2 production in rats with severe steatosis. ET-1, which mainly acts as a vasoconstrictor via the $\mathrm{ET}_{\mathrm{A}}$ receptor on smooth muscle cells, is also overexpressed in rats with severe steatosis, and its serum concentration is elevated. Both the $\mathrm{ET}_{\mathrm{A}}$ and $\mathrm{ET}_{\mathrm{B}}$ receptors seem to be unaltered. The role of endothelin in the increase in intrahepatic resistance has been demonstrated in classical models of cirrhotic portal hypertension ${ }^{16-18}$ and has also been implicated in the pathogenesis of portal hypertension and its complications, especially portopulmonary hypertension. We conclude that an imbalance between vasoconstrictor and vasodilator substances, caused by an overproduction of vasoconstrictors TXA2 and ET-1, is an important contributor to the dynamic component of the increase in intrahepatic resistance in severe steatosis. As both vasoconstrictors are produced by the endothelial cell, these findings support the hypothesized crucial role of the endothelium in the increased intrahepatic resistance.

To further elucidate the underlying mechanisms of the observed increase in intrahepatic resistance and to study a potential static (morphological) factor, we made vascular corrosion casts to visualize the anatomy of the sinusoidal vascular bed. Filling of the blood vessels with a casting polymer and subsequent removal of all the surrounding tissue allows for an accurate and three-dimensional study of the vascular structures by scanning electron microscopy at high levels of magnification that cannot be achieved by angiography-based imaging techniques, which do not attain the same resolution at the microvascular level. ${ }^{26,39}$ The casts of the animals with steatosis showed a marked alteration of liver microvascular architecture. The classical ordering of sinusoids in parallel lines and separated by regular trabeculae of hepatocytes was replaced by a completely disorganized pattern of irregular and flattened blood vessels with numerous interconnections and the presence of multiple 'blebs', that is, blind-ending rounded extensions of the sinusoids, which might represent obstructed sinusoids or leakage by disruption of the normal sinusoidal wall. As recently data on the role of neoangiogenesis in NAFLD have emerged, one could hypothesize that these blebs might represent areas of neoangiogenesis (reinforcing the central role of endothelial cells in the altered intrahepatic resistance). ${ }^{40,41}$ Their true significance remains currently unclear. The disruption of the regular ordering of blood vessels at the microcirculatory level is likely to be an important static contributor to the intrahepatic resistance, as it can be assumed that blood flow through the chaotic microvascular bed in steatosis is hampered.

The MCD model of steatosis is a well-established model of NAFLD and NASH, ${ }^{42}$ but can be criticized because it lacks the classical metabolic context in which NAFLD usually develops. ${ }^{43,44}$ MCD-fed rats develop NASH and hepatic insulin resistance, but the animals lose visceral and peripheral fat, lose weight and do not experience peripheral insulin resistance. ${ }^{45}$ These features might limit the relevance of findings in this model for the understanding of human disease. In our study, however, we focused on the changes within the liver, which do closely resemble what is seen in human NAFLD. ${ }^{28}$ Therefore, we estimate the MCD model is appropriate to test the hypothesis we formulated. Our findings need, however, to be confirmed in other models of NAFLD and NASH.

Finally, the question arises whether these findings are relevant to human NAFLD. In a study of a subset of obese patients prospectively assessing the presence of NAFLD, portal pressure was indirectly assessed by measuring the hepatic venous pressure gradient (HVPG) via the transjugular route. ${ }^{11}$ We found that about $30 \%$ of the patients had an elevation of their gradient meeting the definition of portal hypertension. The increase in HVPG could not be attributed to advanced fibrosis or cirrhosis, but was related to the presence of severe steatosis. Although we did not directly measure the intrahepatic resistance, the increase in HVPG and hence portal hypertension can reliably be considered an indirect marker of increased intrahepatic resistance in relation to severe steatosis. ${ }^{29}$ It can hence be assumed that also in human NAFLD, intrahepatic resistance is elevated in case of severe steatosis, potentially contributing to the progression from simple steatosis to NASH, and to the steatosis-associated problems in case of liver surgery and transplantation.

\section{CONCLUSIONS}

We demonstrate for the first time, by a direct in situ assessment, a significant increase in intrahepatic resistance with obvious haemodynamic impact in relation to severe steatosis. Both dynamic factors with marked endothelial dysfunction and overproduction of vasoconstrictors, and morphological factors with pronounced architectural derangement of 
sinusoidal anatomy are implicated in its pathogenesis. These changes precede necroinflammatory changes and may represent an important pathophysiological mechanism in the progression of NAFLD to NASH and in other NAFLDassociated problems.

\section{DISCLOSURE/CONFLICT OF INTEREST}

The authors declare no conflict of interest.

1. Bugianesi $E$, Bellentani $S$, Bedogni $G$, et al. Clinical update on nonalcoholic fatty liver disease and steatohepatitis. Ann Hepatol 2008;7: 157-160.

2. Vanni E, Bugianesi $E$, Kotronen A, et al. From the metabolic syndrome to NAFLD or vice versa?. Dig Liver Dis 2010;42:320-330.

3. Bugianesi E, Vanni E, Marchesini G. NASH and the risk of cirrhosis and hepatocellular carcinoma in type 2 diabetes. Curr Diab Rep 2007;7: 175-180.

4. Behrns KE, Tsiotos GG, DeSouza NF, et al. Hepatic steatosis as a potential risk factor for major hepatic resection. J Gastrointest Surg 1998;2:292-298.

5. Zamboni F, Franchello A, David E, et al. Effect of macrovescicular steatosis and other donor and recipient characteristics on the outcome of liver transplantation. Clin Transplant 2001;15:53-57.

6. Gilgenkrantz $\mathrm{H}$, Collin de l'Hortet $\mathrm{A}$. New insights into liver regeneration. Clin Res Hepatol Gastroenterol 2011;35:623-629.

7. Targher G, Chonchol M, Pichiri l, et al. Risk of cardiovascular disease and chronic kidney disease in diabetic patients with non-alcoholic fatty liver disease: just a coincidence?. J Endocrinol Invest 2011;34: 544-551.

8. Seifalian AM, Piasecki C, Agarwal A, et al. The effect of graded steatosis on flow in the hepatic parenchymal microcirculation. Transplantation 1999;68:780-784.

9. Farrell GC, Teoh NC, McCuskey RS. Hepatic microcirculation in fatty liver disease. Anat Rec (Hoboken) 2008;291:684-692.

10. Francque $S$, Wamutu $S$, Chatterjee $S$, et al. Non-alcoholic steatohepatitis induces non-fibrosis-related portal hypertension associated with splanchnic vasodilation and signs of a hyperdynamic circulation in vitro and in vivo in a rat model. Liver Int 2010;30:365-375.

11. Francque $S$, Verrijken $A$, Mertens I, et al. Non-cirrhotic human NAFLD induces portal hypertension in relation to the histological degree of steatosis. Eur J Gastroenterol Hepatol 2010;22:1449-1457.

12. Larter CZ. Not all models of fatty liver are created equal: understanding mechanisms of steatosis development is important. J Gastroenterol Hepatol 2007;22:1353-1354.

13. Kleiner DE, Brunt EM, Van Natta M, et al. Design and validation of a histological scoring system for nonalcoholic fatty liver disease. Hepatology 2005;41:1313-1321.

14. Heinrich PC, Castell JV, Andus T. Interleukin- 6 and the acute phase response. Biochem J 1990;265:621-636.

15. Laleman W, Van Landeghem L, Van der Elst I, et al. Nitroflurbiprofen, a nitric oxide-releasing cyclooxygenase inhibitor, improves cirrhotic portal hypertension in rats. Gastroenterology 2007;132:709-719.

16. Barton $M$, Yanagisawa $M$. Endothelin: 20 years from discovery to therapy. Can J Physiol Pharmacol 2008;86:485-498.

17. Takashimizu $S$, Kojima $S$, Nishizaki $Y$, et al. Effect of endothelin A receptor antagonist on hepatic hemodynamics in cirrhotic rats. Implications for endothelin-1 in portal hypertension. Tokai J Exp Clin Med 2011;36:37-43.

18. Cavasin MA, Semus $H$, Pitts $K$, et al. Acute effects of endothelin receptor antagonists on hepatic hemodynamics of cirrhotic and noncirrhotic rats. Can J Physiol Pharmacol 2010;88:636-643.

19. Gupta TK, Toruner M, Chung MK, et al. Endothelial dysfunction and decreased production of nitric oxide in the intrahepatic microcirculation of cirrhotic rats. Hepatology 1998;28:926-931.

20. Wiest R, Groszmann RJ. The paradox of nitric oxide in cirrhosis and portal hypertension: too much, not enough. Hepatology 2002;35: 478-491.
21. Feletou M, Huang $Y$, Vanhoutte PM. Endothelium-mediated control of vascular tone: COX-1 and COX-2 products. Br J Pharmacol, 2011;164: 894-912.

22. Gracia-Sancho J, Lavina B, Rodriguez-Vilarrupla A, et al. Enhanced vasoconstrictor prostanoid production by sinusoidal endothelial cells increases portal perfusion pressure in cirrhotic rat livers. J Hepatol 2007:47:220-227.

23. Bradley P, Priebat DA, Christensen R, et al. Relation of peroxidase activity in gut mucosa to inflammation. Am J Physiol Regul Integr Comp Physiol 1978;234:R72-R79.

24. Giakoustidis $D E$, Giakoustidis $A E$, lliadis $S$, et al. Attenuation of liver ischemia/reperfusion induced apoptosis by epigallocatechin-3-gallate via down-regulation of NF-kappaB and c-Jun expression. J Surg Res 2010;159:720-728.

25. Bessems $M$, 't Hart NA, Tolba $R$, et al. The isolated perfused rat liver: standardization of a time-honoured model. Lab Anim 2006;40:236-246.

26. Van Steenkiste C, Trachet B, Casteleyn C, et al. Vascular corrosion casting: analyzing wall shear stress in the portal vein and vascular abnormalities in portal hypertensive and cirrhotic rodents. Lab Invest 2010;90:1558-1572.

27. McCuskey RS, Ito Y, Robertson GR, et al. Hepatic microvascular dysfunction during evolution of dietary steatohepatitis in mice. Hepatology 2004;40:386-393.

28. Brunt EM. Histopathology of non-alcoholic fatty liver disease. Clin Liver Dis 2009:13:533-544.

29. Laleman W, Landeghem L, Wilmer A, et al. Portal hypertension: from pathophysiology to clinical practice. Liver Int 2005;25:1079-1090.

30. Ait-Oufella $\mathrm{H}$, Maury $\mathrm{E}$, Lehoux $\mathrm{S}$, et al. The endothelium: physiological functions and role in microcirculatory failure during severe sepsis. Intensive Care Med 2010;36:1286-1298.

31. Thabut D, Shah V. Intrahepatic angiogenesis and sinusoida remodeling in chronic liver disease: new targets for the treatment of portal hypertension?. J Hepatol 2010;53:976-980.

32. Espinola-Klein C, Gori T, Blankenberg S, et al. Inflammatory markers and cardiovascular risk in the metabolic syndrome. Front Biosci 2011;16:1663-1674.

33. Cusi K. Role of insulin resistance and lipotoxicity in non-alcoholic steatohepatitis. Clin Liver Dis 2009;13:545-563.

34. Bugianesi E, McCullough AJ, Marchesini G. Insulin resistance: a metabolic pathway to chronic liver disease. Hepatology 2005;42:987-1000.

35. Pasarin M, Abraldes JG, Rodriguez-Vilarrupla A, et al. Insulin resistance and liver microcirculation in a rat model of early NAFLDJ Hepatol 2011;55:1095-1102.

36. Lee $\mathrm{CH}$, Loureiro-Silva MR, Abraldes JG, et al. Decreased intrahepatic response to alpha(1)-adrenergic agonists in lipopolysaccharidetreated rats is located in the sinusoidal area and depends on Kupffer cell function. J Gastroenterol Hepatol 2007;22:893-900.

37. Graupera M, Garcia-Pagan JC, Abraldes JG, et al. Cyclooxygenasederived products modulate the increased intrahepatic resistance of cirrhotic rat livers. Hepatology 2003;37:172-181.

38. Yokoyama $\mathrm{Y}, \mathrm{Xu} \mathrm{H}$, Kresge $\mathrm{N}$, et al. Role of thromboxane $\mathrm{A} 2$ in early BDL-induced portal hypertension. Am J Physiol Gastrointest Live Physiol 2003;284:G453-G460.

39. Casteleyn C, Trachet B, Van Loo D, et al. Validation of the murine aortic arch as a model to study human vascular diseases. J Anat 2010;216:563-571.

40. Coulon S, Heindryckx F, Geerts A, et al. Angiogenesis in chronic liver disease and its complications. Liver Int 2011;31:146-162.

41. Coulon S, Francque $\mathrm{S}$, Colle $\mathrm{I}$, et al. Evaluation of inflammatory and angiogenic factors in patients with non-alcoholic fatty liver disease. Cytokine 2012;59:442-449.

42. Fan JG, Qiao L. Commonly used animal models of non-alcoholic steatohepatitis. Hepatobiliary Pancreat Dis Int 2009;8:233-240.

43. Rinella ME, Elias MS, Smolak RR, et al. Mechanisms of hepatic steatosis in mice fed a lipogenic methionine choline-deficient diet. J Lipid Res 2008:49:1068-1076.

44. Larter CZ, Yeh MM. Animal models of NASH: getting both pathology and metabolic context right. J Gastroenterol Hepatol 2008:23:1635-1648.

45. Rinella ME, Green RM. The methionine-choline deficient dietary model of steatohepatitis does not exhibit insulin resistance. J Hepatol 2004;40:47-51. 